$\underline{\text { Avicenna Journal of Nursing and Midwifery Care - ISSN 2676-5748 }}$

\title{
Investigate the Relationship Between Self-Care, Health Literacy and Social Support in Patients with Hypertension Referring to the Specialized Heart Clinic of Tohid Hospital in Sanandaj
}

\author{
Rozhin Bahmani ${ }^{1}$, Nazila Olyaie ${ }^{2}$, Sonia Darvishi ${ }^{3}$, Neda Sheikhakaryaee ${ }^{4 *}$
}

1. Student, Faculty of Nursing and Midwifery, Kurdistan University of Medical Sciences, Sanandaj, Iran

2. Instractor, Faculty of Nursing and Midwifery, Kurdistan University of Medical Sciences, Sanandaj, Iran

3. Statistics Consultant, Faculty of Nursing and Midwifery, Kurdistan University of Medical Sciences, Sanandaj, Iran

4. Assistant Professor, Faculty of Nursing and Midwifery, Kurdistan University of Medical Sciences, Sanandaj, Iran

\begin{tabular}{|c|c|}
\hline Article Info & ABSTRACT \\
\hline Received: 2020/08/03; & $\begin{array}{l}\text { Introduction: Self-care in hypertension is one of the most significant strategies in order to } \\
\text { control the disease; moreover, health literacy and social support are regarded as effective factors }\end{array}$ \\
\hline $\begin{array}{l}\text { Accepted: 2020/09/06; } \\
\text { Published Online: 2021/09/21 } \\
\text { doil 10.30699/ajnmc.29.3.190 }\end{array}$ & $\begin{array}{l}\text { in this case. Therefore, considering the necessity and need of society in promoting the level of } \\
\text { health literacy and social support, as well as the role and importance of self-care in hypertension, } \\
\text { the aim of the present study was to determine the relationship among self-care behavior and } \\
\text { health literacy and social support in patients suffering from hypertension. }\end{array}$ \\
\hline
\end{tabular}

Original Article

Use your device to scan and read the article online

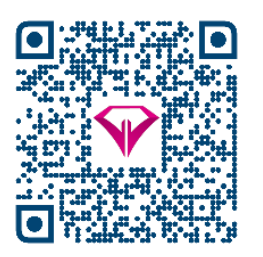

Methods: The descriptive-analytical study was cross-sectional and was conducted on 400 patients with hypertension referring to the specialized heart clinic of Tohid Hospital in Sanandaj, Iran, using the convenience sampling method. The Four-part Demographic Questionnaire, the Self-Care Behavior Assessment Questionnaire, the Health Literacy for Iranian Adults Questionnaire and Social Support Questionnaire were used so as to collect the data. To analyze the data, SPSS software version 21 and parametric tests of Pearson correlation coefficient and non-parametric Kruskal-Wallis analysis were used.

Results: The findings indicated that mean and standard deviation of Self-Care Behavior Score and Health Literacy and Social Support were 38/64 \pm 8/83, 63/10 \pm 11/16 and 91/54 \pm $6 / 93$, respectively. There was a Positive significant relationship between Self-Care Behavior and Health Literacy (r=0/491, $P$ value $=0 / 00)$, Self-Care Behavior and Social Support (r=0/322, $P$ value $=0 / 00)$, Social Support and Health Literacy $(\mathrm{r}=0 / 337, P$ value $=0 / 00)$.

Conclusion: The results of the present study showed that having health literacy and social support would influence the individual and the occurrence of self-care behaviors, and since these cases are highly effective in preventing and controlling hypertension, it is necessary to train and promote them in the health system.

Keywords: Hypertension, Self-care, Health literacy, Social support

Corresponding Information:

Neda Sheikhakaryaee, Assistant Professor, Faculty of Nursing and Midwifery, Kurdistan University of Medical Sciences, Sanandaj, Iran. Email: n.akaryaie@gmail.com

Copyright $\odot$ 2021, This is an original open-access article distributed under the terms of the Creative Commons Attribution-noncommercial 4.0 International License which permits copy and redistribution of the material just in noncommercial usages with proper citation.

How to Cite This Article:

Bahmani R, Olyaie N, darvishi S, Sheikhakaryaee N. Investigate the Relationship Between Self-Care, Health Literacy and Social Support in Patients with Hypertension Referring to the Specialized Heart Clinic of Tohid Hospital in Sanandaj. Avicenna J Nurs Midwifery Care. 2021; 29 (3) :190-200 
بررسى ارتباط خودمراقبتى، سواد سلامت و حمايت اجتماعى در بيماران مبتلا به فشارخون مراجعهكننده به كلينيك تخصصى قلب بيمارستان توحيد سنندج

روزين بهمنى'، نازيلا عليايى'، سونيا درويشى ‘ّ، ندا شيخ ذكريايیى

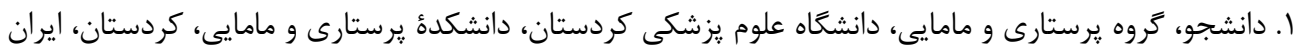

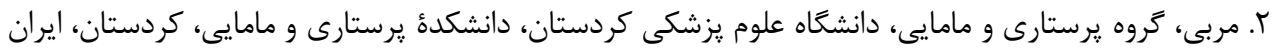

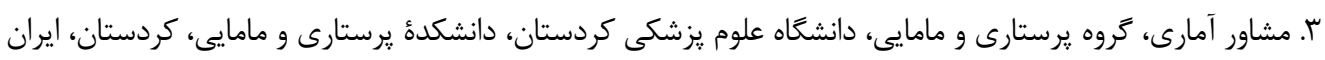

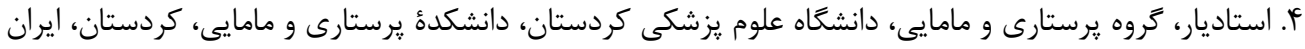

\begin{tabular}{|c|c|}
\hline جكيده & اطلاعات مقاله \\
\hline 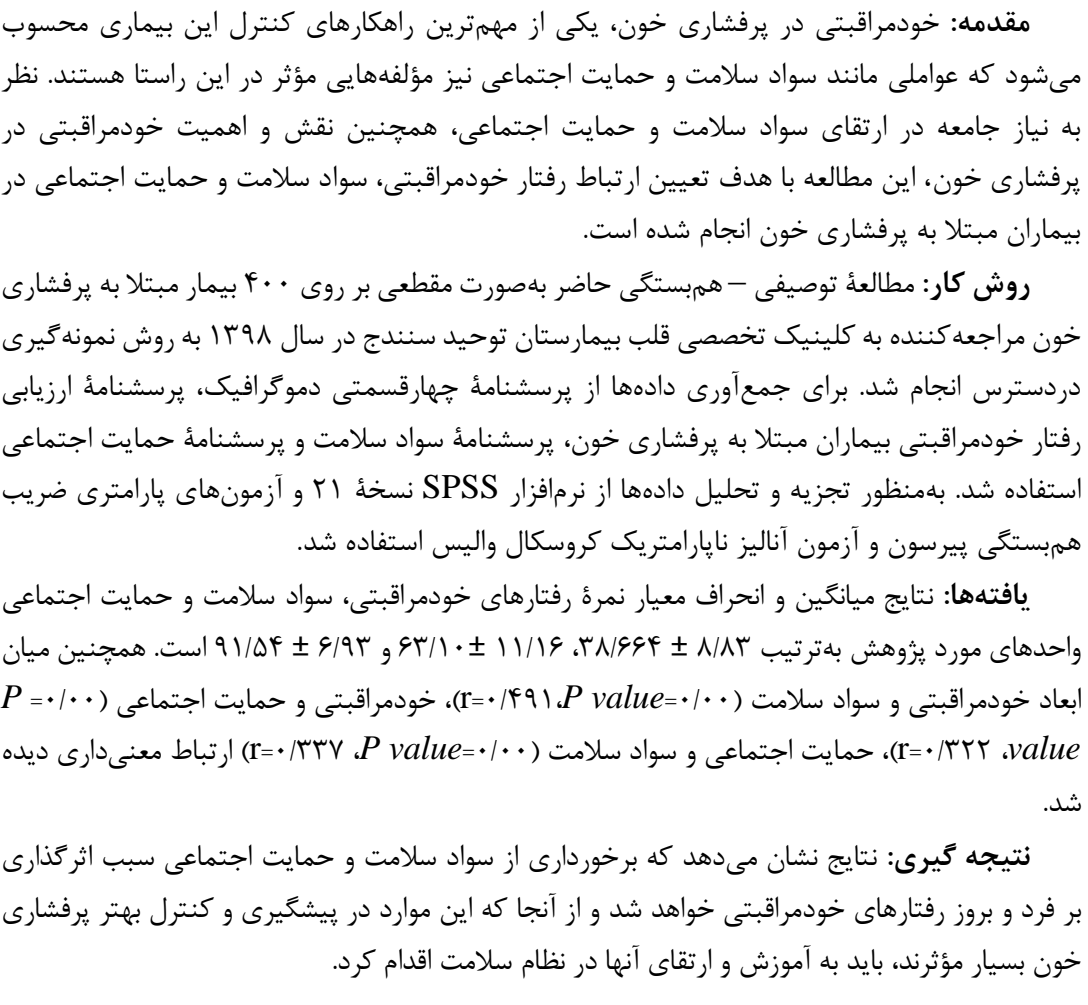 & 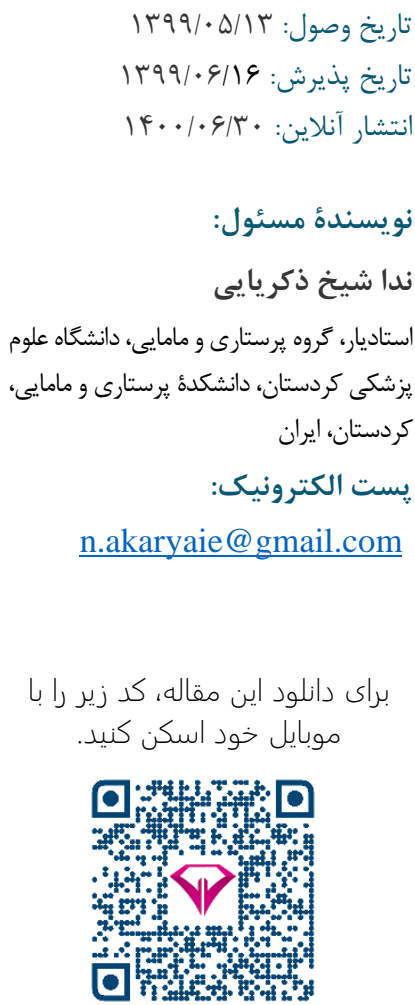 \\
\hline كليدوازهها: يرفشارى خون، خودمراقبتى، سواد سلامت، حمايت اجتماعى & \\
\hline
\end{tabular}

مقدمه

را تحت تأثير قرار مى دهند؛ بهطورى كه بيمار نهتنها ناجار است

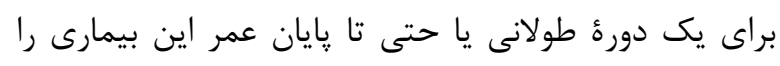
تحمل كند، بلكه بايد با عوارض ناشى از آن كنار بيايد و خود

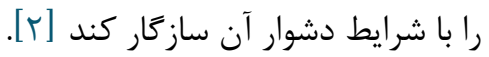

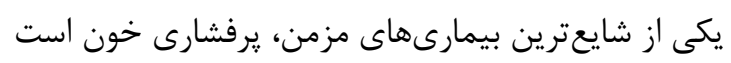

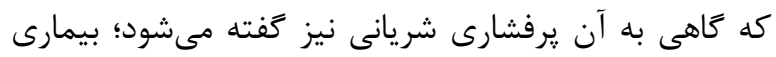

در آستانهُ قرن الT ميلادى، يكى از برجستهترين وقايعى

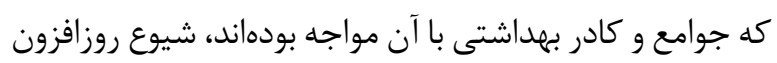
بيمارىهاى مزمن بوده است كه عادات و رفتارهاى بهداشتى

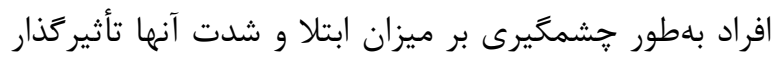

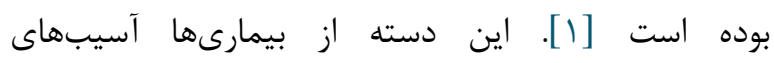
جبران نايذيرى به دنبال دارند و بهشدت كيفيت زندكى بيماران 
يرفشارى خون تأثير گذار باشند. از جمله اين عوامل مىتوان به

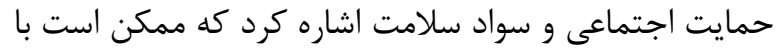
خودمراقبتى ارتباط داشته باشند. سواد سلامت، حاصل

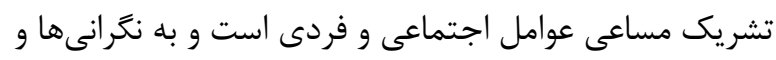
ابعاد سواد در زمينهٔ سلامت مىيردازد و شاخص حياتى و و مهمى در نتايج و هزينههاى مراقبتهاى بهداشتى شناخته

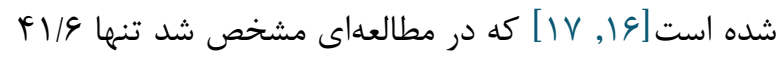
درصد از بيماران مبتلا به يرفشارى خون در ايران سطح سواد سلامت كافى داشتند [1/1)].

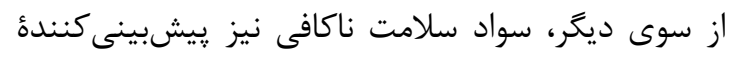

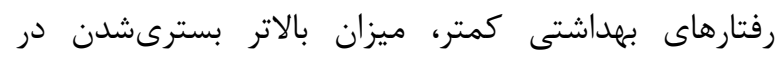
بيمارستان، دشوارى در برقرارى ارتباط كلامى با ارائهدهندكان

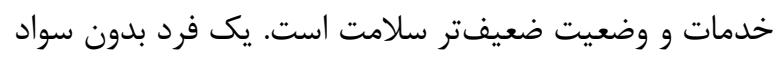

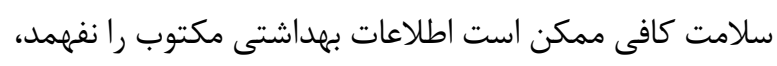

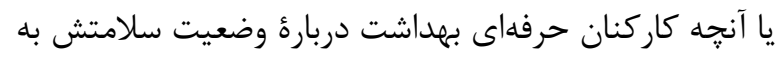

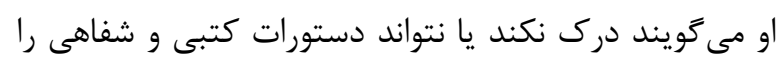

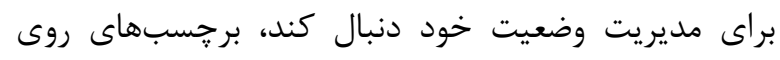

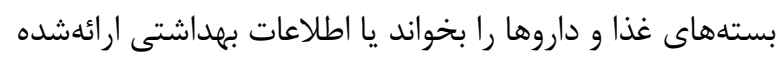

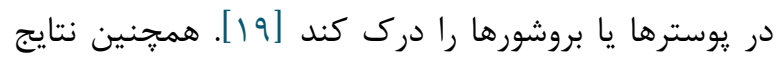

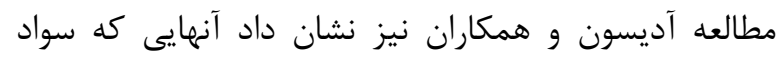

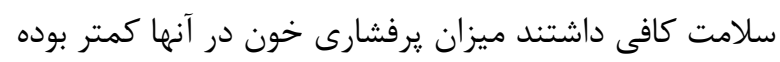

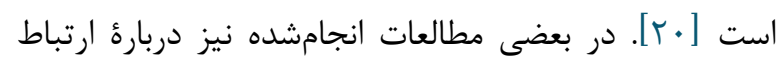

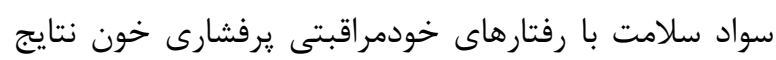

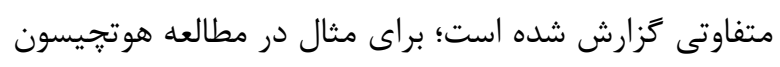
و همكاران و اينكرام و همكاران بين سواد سلامت و و رفتارهاى

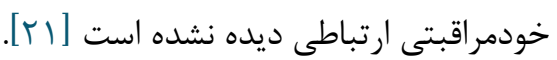

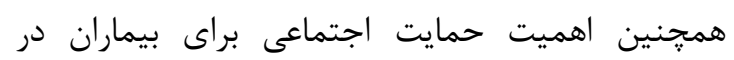
مديريت بيمارىهاى مزمن از ديرباز شناخته شده است.

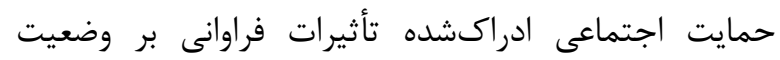

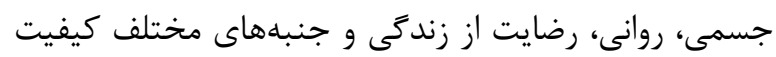

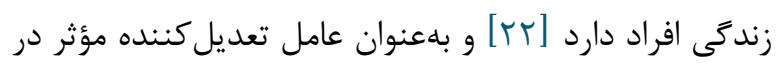

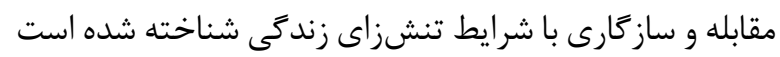

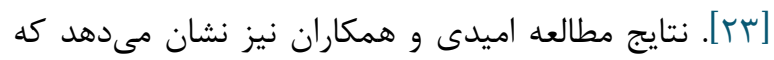

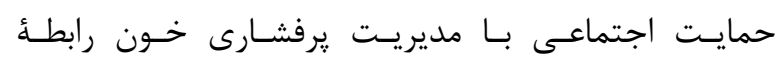

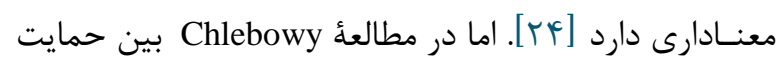

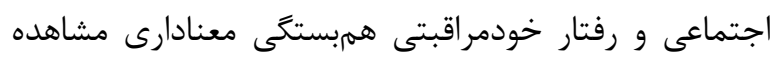

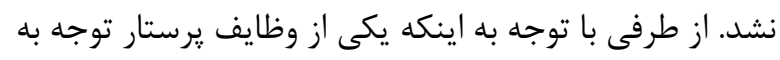

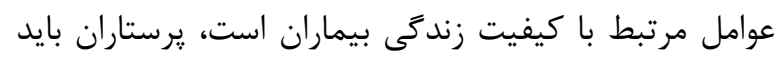

مزمنى كه در آن فشارخون در شريانها بالا مىرود. يرفشارى

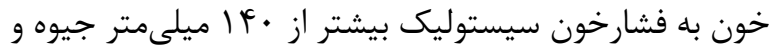
فشار دياستوليك بيشتر از •9 ميلىمتر جيوه اطلاق مىشود إنى

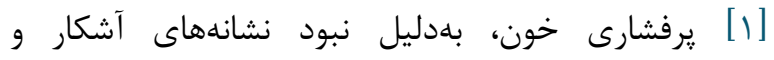

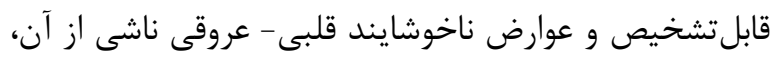

به قاتل خاموش معروف است [ب].

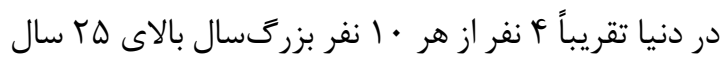

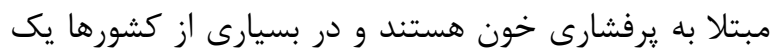

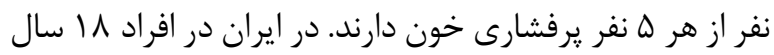

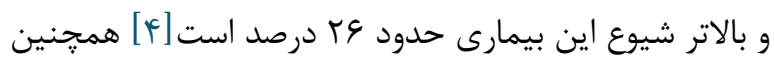

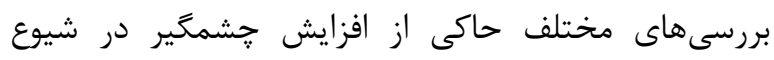

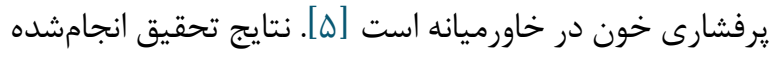

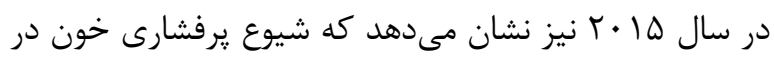

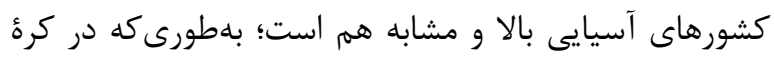

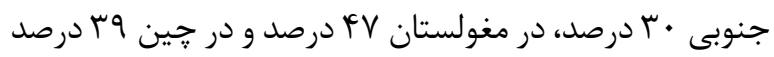

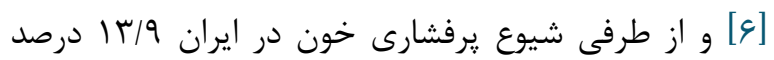

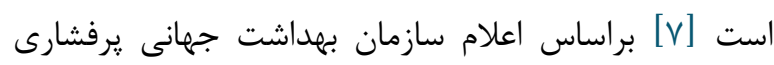

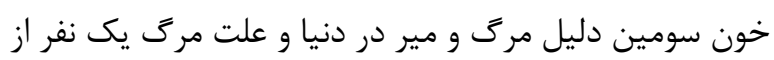

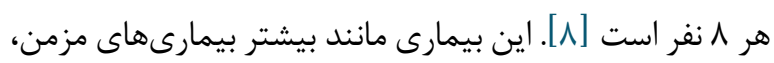

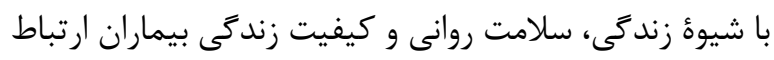

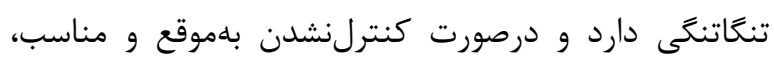
موجب بروز بيمارىهاى مختلف، ايجاد ناتوانى قابلتوجنه دونه

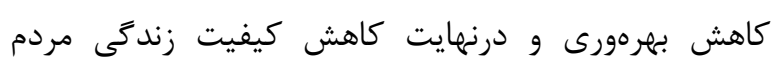
مىشود [9, · [1]. با توجه به اينكه بيمارى مزمن نيازمند مراقبت مزمن است،

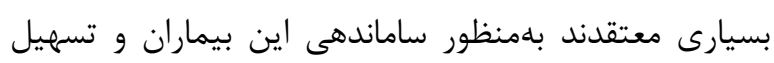

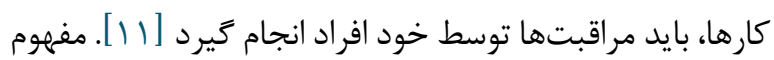

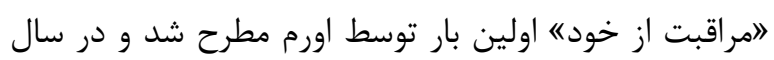

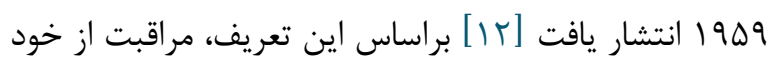

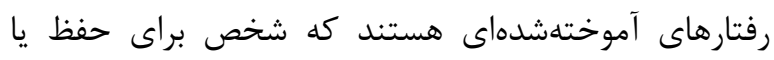

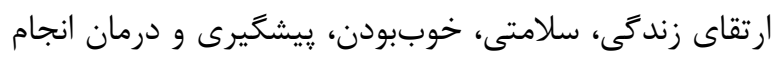

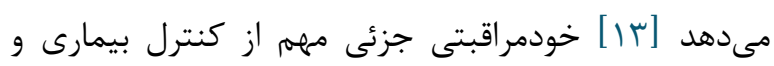

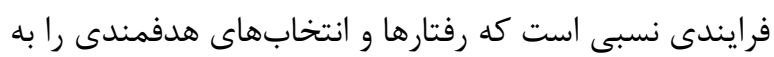

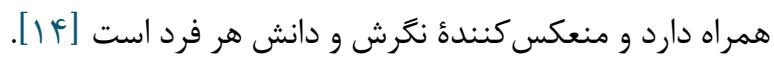

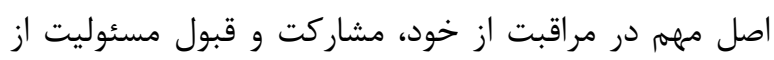

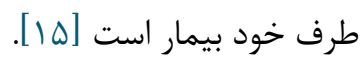

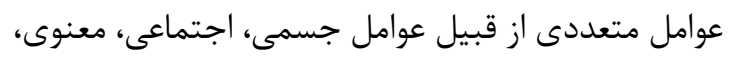

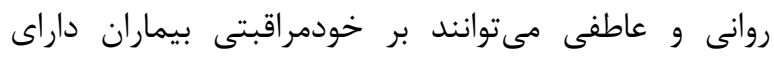


تحصيلات، تأهل، اشتغال، بيمهٔ درمانى، سابقهُ خانوادَى و

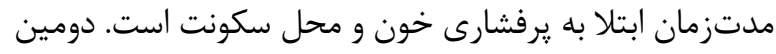

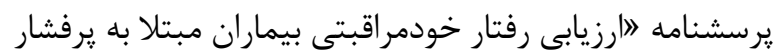

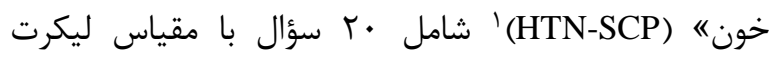

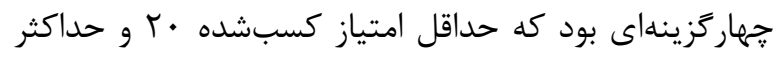

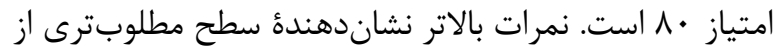

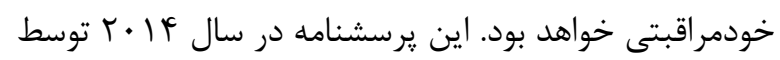
Han

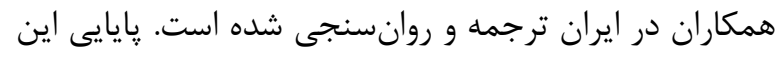

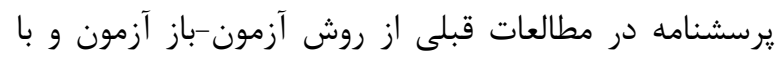

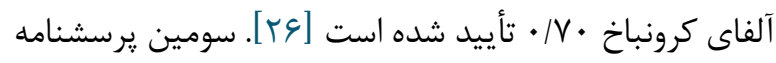

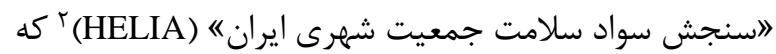

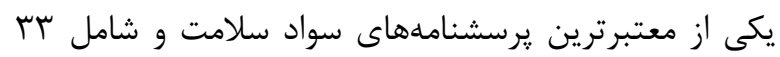

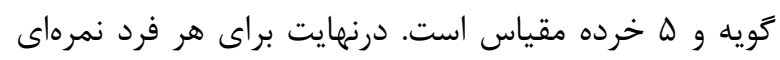

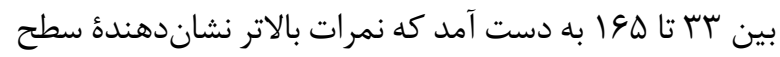

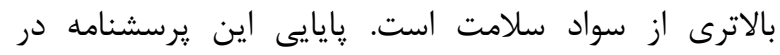

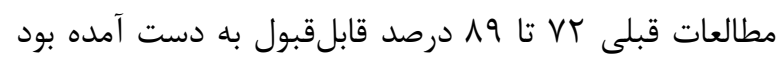

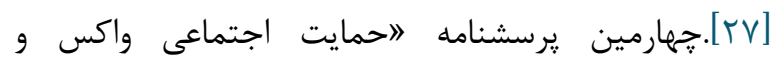

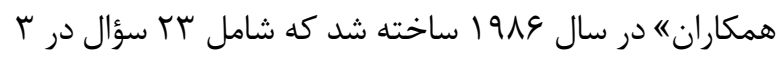

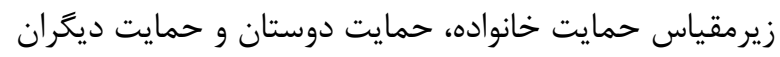

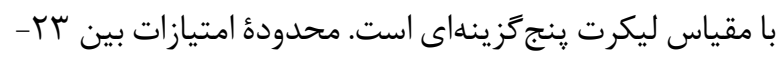

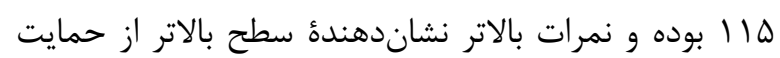

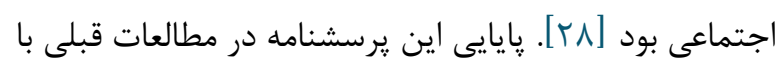

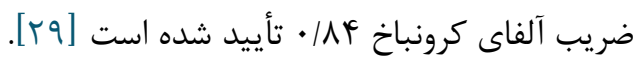

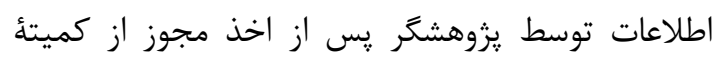

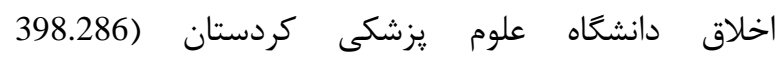
دانشكاة برستارى و.MEC.

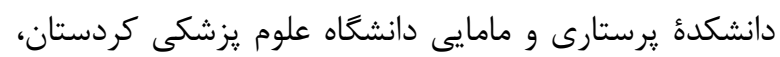

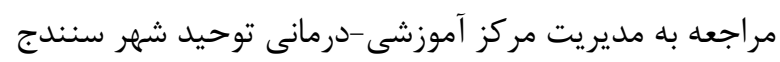

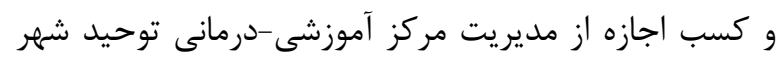

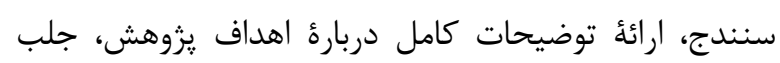

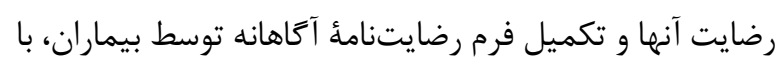

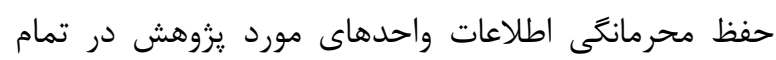
مراحل يزوهش، جمع آورى شد.

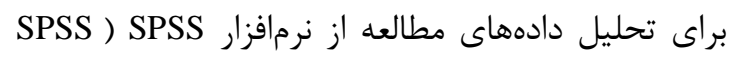
نسخd r Inc., Chicago, Ill., USA

. Health Literacy for Iranian Adults (HELIA) ${ }^{r}$

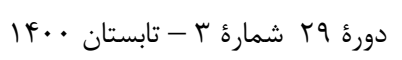

حمايت از بيمار را از وظايف اخلاقى و حرفهاى خود بدانند و با اعمال و فعاليتهاى متنوع خود به حمايت اجتماعى بيمار

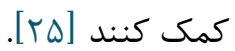
بنابر اين نظر به ضرورت و نياز جامعه در ارتقاى سطح سواد سلامت و حمايت اجتماعى و همجنين نقش و اهميت

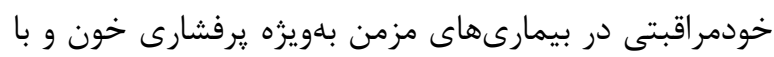

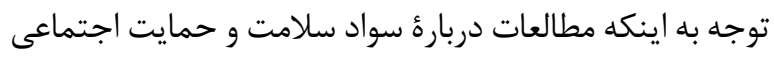
بيماران مبتلا به برفشارى خون در كشورهاى ديخر و در كشور ما نتايج متفاوتى داشته است و نظر به اينكه مطالعات محدودى دئل

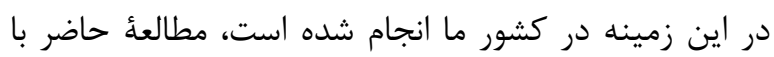

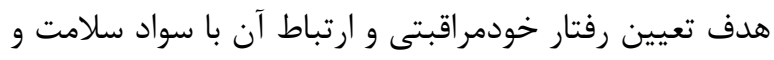

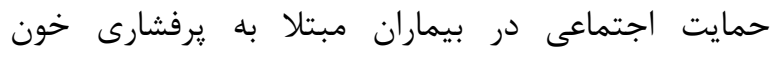

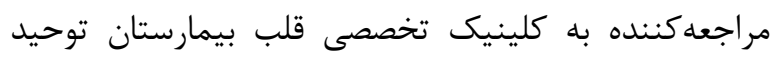

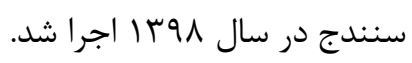

$$
\text { روش كار }
$$

يزوهش حاضر توصيفى - همبستگى و بلصورت مقطعى آماري

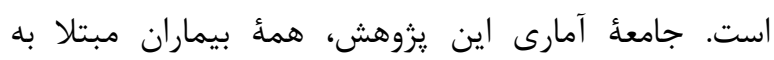

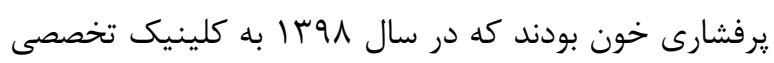
قلب بيمارستان توحيد سنندج مراجعه كردند. حجم نمونه با باري

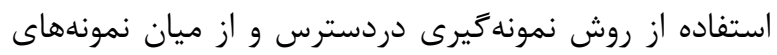

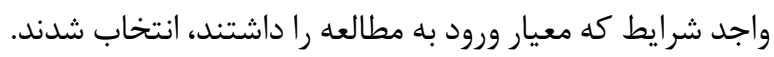

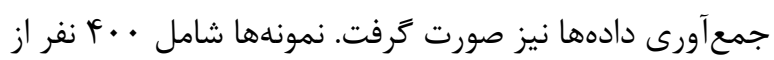

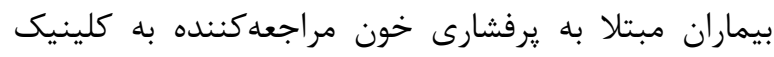

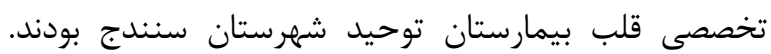

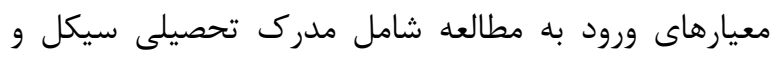
بالاتر، دامنٔ سنى 11 تا VD سال، داشتن فشارخون اوليه

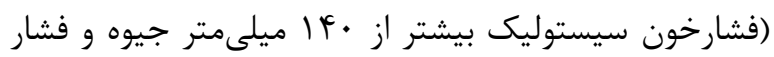

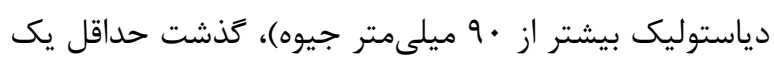

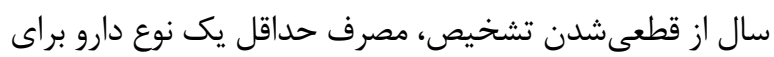

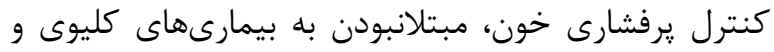

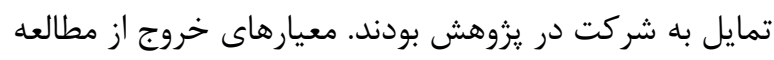

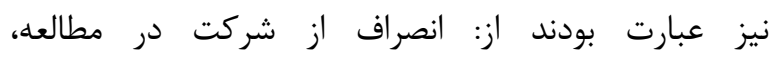
يرسشنامههاى ناقص و بدحال شدن بيمار.

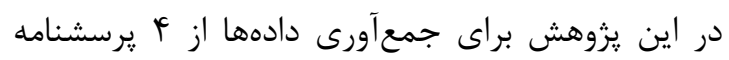

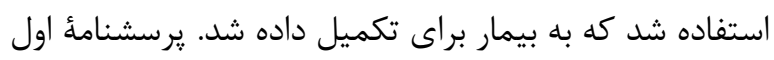
شامل مشخصات دموكرافيك از قبيل سن، جنسيت و ميزان ' Hypertension Self-Care Profile' مجله مراقبت يرستارى و مامايى ابنسينا 
متغير خودمراقبتى ارتباط معنى دارى (ه •/• > Palue) وجود ندارد. درخصوص مدتزمان ابتلا به يرفشارى خون، بيشترين

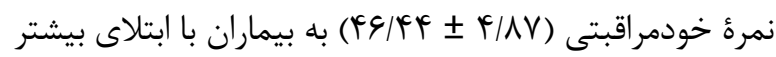

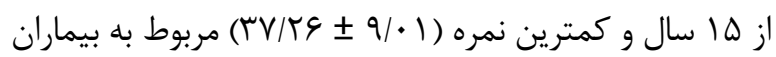

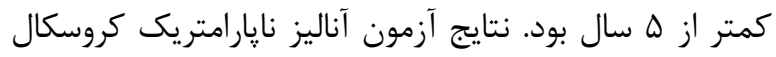

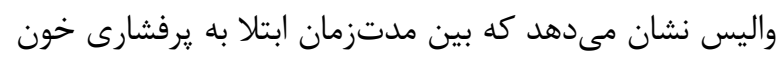

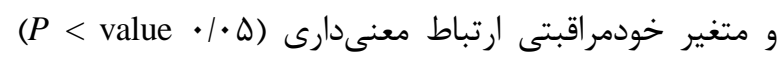

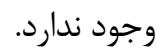
براساس تحليل آمارى بين محل سكونت و متغير

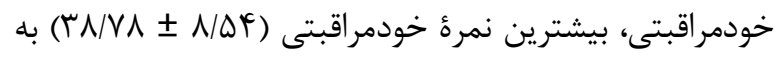

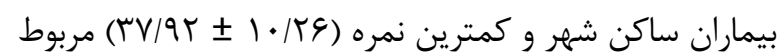
به بيماران ساكن روستا بود. نتايج آزمون آناليز نايارامتريك

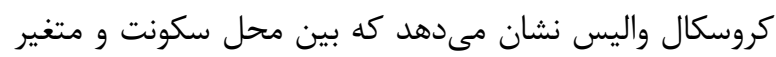

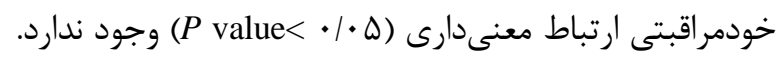

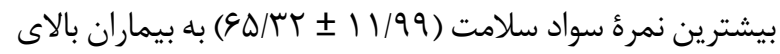

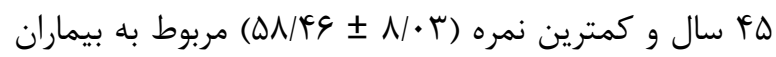

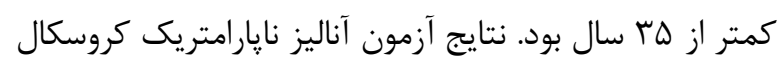

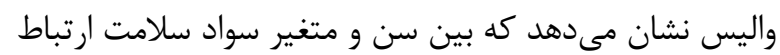

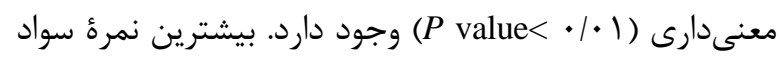

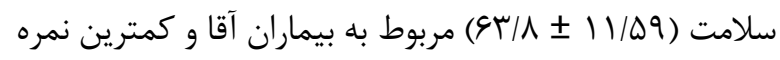

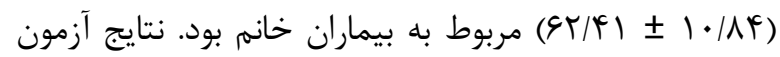

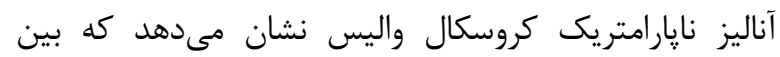
جنسيت و متغير سواد سلامت ارتباط معنى دارى (ه •/ > > value

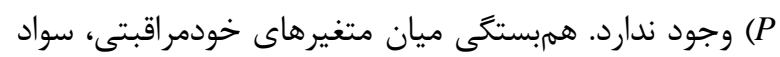
سلامت و حمايت اجتماعى در بيماران مبتلا به برفشارى خون در جدول r آمده است.
شاخصهاى تمركز و يراكندگى ميزان سواد سلامت و حمايت اجتماعى در رفتار خودمراقبتى بهصورت كلى و برحسب

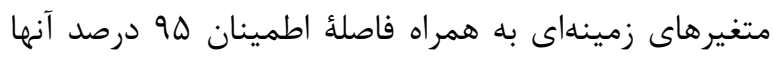

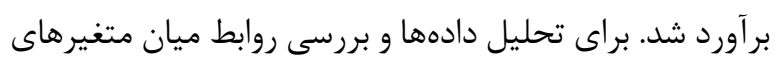
مختلف ابتدا از آزمون كولموكروف - اسميرنوف استفاده شد،

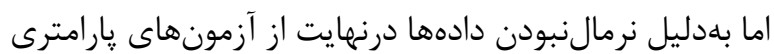

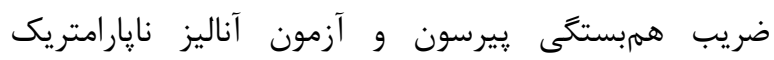

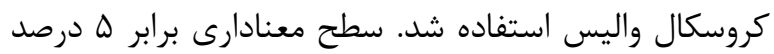

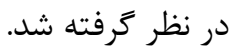

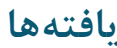

در مطالعٔ حاضر 9 و نفر (UV/T درصد) از بيماران را زنان

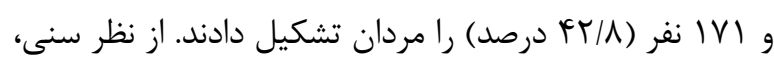

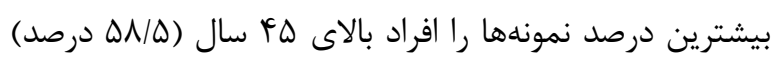
تشكيل دادند. تحليلهاى آمارى درباره محل سكونت نشان داد داد

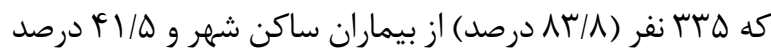

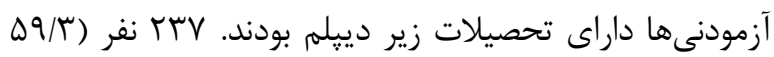

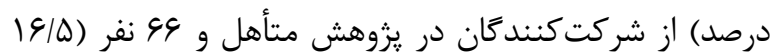

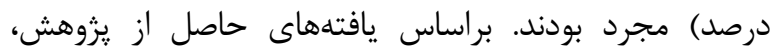

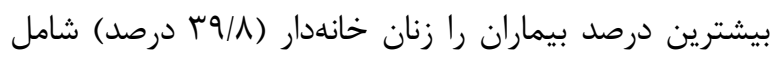

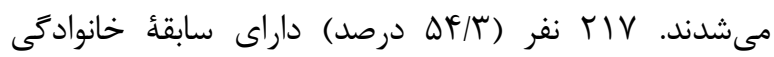
فشارخون بودند. براساس يافتههاى بلهدستآمده بيشترين تعداد

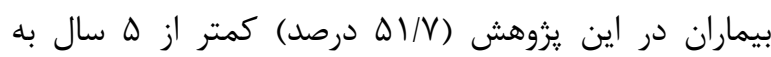

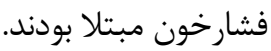
در مطالعُ حاضر بيشترين نمره خودمراقبتى (N/AF

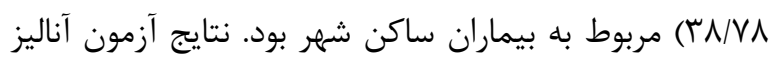

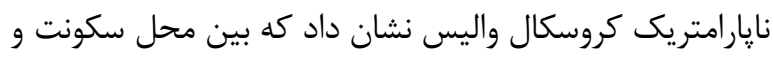

جدول ا. توزيع فراوانى مشخصات دموكرافيك بيماران مبتلا به يرفشارى خون مراجعه كننده به كلينيك تخصصى قلب بيمارستان توحيد

متغير تعداد درصد

سن

$r \Delta / T|+| F \Delta-r \Delta$

N/\& TF $\Delta D-F Q$

$I V / \Delta V+\varphi \Delta-\Delta \varphi$

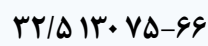

جنس زن و

مرد

سطح تحصيلات سيكل \$9 ه 199 


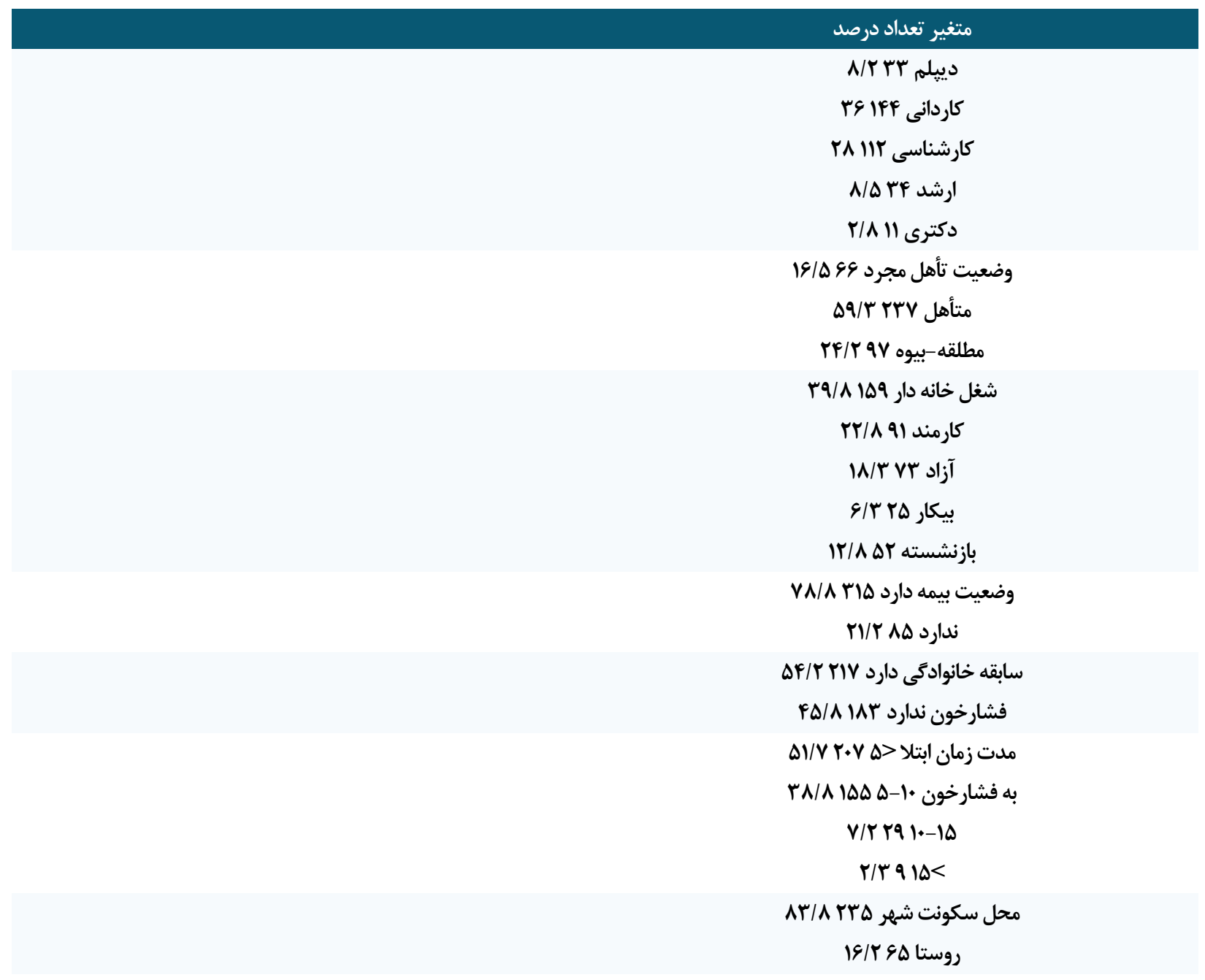

\begin{tabular}{|c|c|c|c|}
\hline $\mathrm{P}$ & انحراف معيار & ميانكين & متغيرها \\
\hline $.1 . \cdot 1$ & NAT & TNGF & خود مراقبتى \\
\hline $.1 \cdot .1$ & $11 / 19$ & $9 \pi / 1$. & سواد سلامت \\
\hline $.1 \cdot 1$ & 8/9 & $91 / Q f$ & حمايت اجتماعى \\
\hline ورد يزوهش برابر سو/q & ديزان حمايت & \multicolumn{2}{|c|}{ 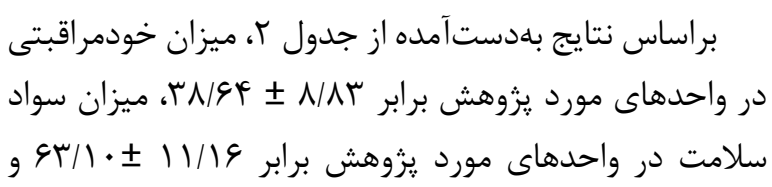 } \\
\hline
\end{tabular}

جدول r. بررسى هم بستخى ميان متغيرهاى خودمراقبتى، سواد سلامت و حمايت اجتماعى در بيماران مبتلا به يرفشارى خون مراجعه

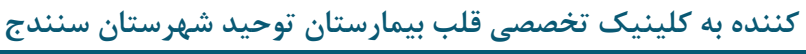

\begin{tabular}{|c|c|c|c|}
\hline حمايت اجتماعى & سواد سلامت & خود مراقبتى & متغير ها \\
\hline $\begin{array}{c}\mathrm{p} \text { value }=\cdot / \cdot \cdot \\
\mathrm{r}=\cdot / \mathrm{rTr}\end{array}$ & $\begin{array}{c}\mathrm{p} \text { value }=\cdot / \cdot \cdot \\
\mathrm{r}=\cdot / 4 q 1\end{array}$ & 1 & خود مراقبتى \\
\hline $\begin{array}{c}\mathrm{p} \text { value }=\cdot / \cdot . \\
\mathrm{r}=\cdot / \mu \mathrm{r} v\end{array}$ & 1 & $\begin{array}{c}\mathrm{p} \text { value }=\cdot / \cdot . \\
\mathrm{r}=\cdot / \uparrow q 1\end{array}$ & سواد سلامت \\
\hline
\end{tabular}




\begin{tabular}{|c|c|c|c|}
\hline حمايت اجتماعى & سواد سلامت & خود مراقبتى & متغيرها \\
\hline 1 & $\begin{array}{c}\mathrm{p} \text { value }=\cdot / \cdot \cdot \\
\mathrm{r}=\cdot / \mathrm{r} \mathrm{v}\end{array}$ & $\begin{array}{c}\mathrm{p} \text { value }=\cdot / \cdot \cdot \\
\mathrm{r}=\cdot / \mathrm{rr}\end{array}$ & , \\
\hline
\end{tabular}

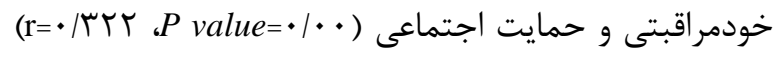

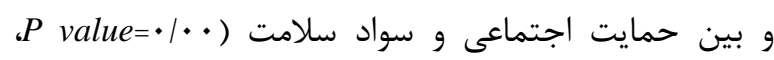

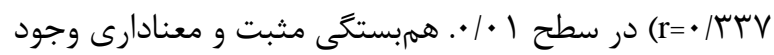

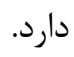

بامنظور بررسى همبستخى متغيرهاى خودمراقبتى، سواد

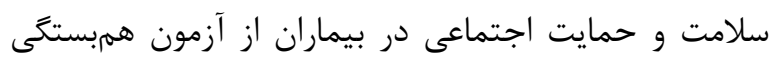

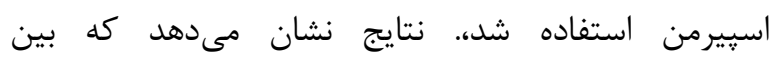

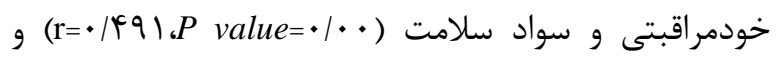

جدول f. نتايج ركرسيون خطى (Backward) براى تأثير يِيشَويى حمايت اجتماعى، سواد سلامت و دموكرافيك بر خودمراقبتى فئى

\begin{tabular}{|c|c|c|c|}
\hline Sig. & t آماره t & ضريب رَرسيونى & متغير \\
\hline$\cdot, \cdots$ & $\Delta, \xi$ & $\Delta \cdot, T$ & (ثابت) \\
\hline$\cdot, \cdots$ & - & $-1,9 \Lambda$ & سطح سواد \\
\hline$\cdot, \cdot 1$ & $-Y, Y \wedge$ & Tr, & وضعيت تأهل \\
\hline$\cdot, \cdot r$ & $r, Y Y$ & $\cdot 19$ & وضعيت اشتغال \\
\hline$\cdot, \cdots$ & $-r, \vee$ & $-\downarrow, \wedge \vee$ & وضعيت بيمه \\
\hline$\cdot, \cdots$ & 9,9 & $\cdot, r q$ & سواد سلامت \\
\hline$\cdot, \cdot 1$ & $-Y, F$ & $-\cdot, 19$ & حمايت اجتماعى \\
\hline \multicolumn{2}{|c|}{$\mathrm{R}^{2}=0.40$} & & \\
\hline
\end{tabular}

بحث

جامعلُ سالمندان مبتلا به يرفشارى خون نيز از يافتههاى مطالعأ

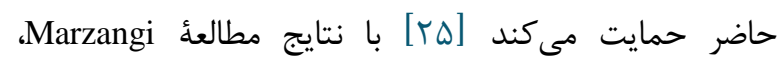

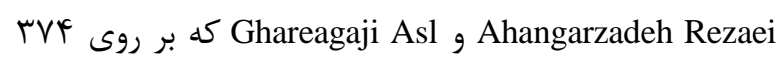
بيمار مبتلا به نارسايى قلبى صورت گرفته بود، همخوانى دارد

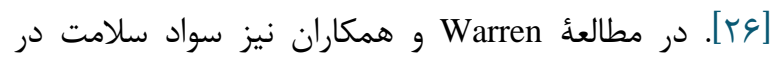
بيماران مبتلا به يرفشارى خون در آمريكا در سطح مطلوبى نبود [rV]

اما نتايج يزوهش Seyedoshohadaee و همكاران و Rafiezadeh و همكاران با نتايج حاضر مغايرت داشت كه

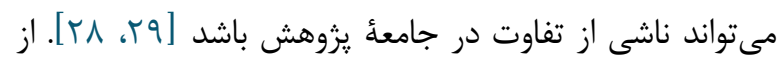

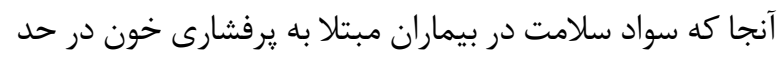
مطلوبى مشاهده نشد و نبود سواد سلامت مطلوب مانعى براى مديريت رفتارهاى خودمراقبتى است، لازم است بخشهاى مناى

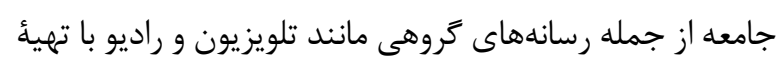
برنامههاى آموزشى و دادن اطلاعات سلامت متناسب با نيازهاو توان مخاطبان براى ارتقاى سواد سلامت همئ افراد جامعه

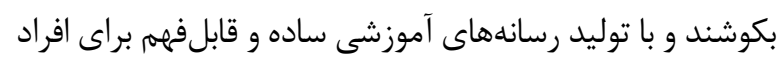
داراى سواد سلامت يايين به آنان كمك كنند تا سطح سواد سلامت خود را بهبود بخشند. علاوه بر اين، متخصصان حرفه
براساس نتايج اين :زوهش، ميانگين و انحراف معيار كلى

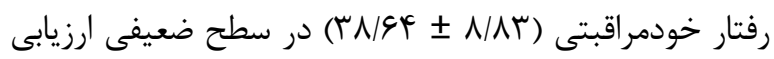
شد كه با نتايج مطالعd Shabibi و همكاران كه ميانگين نمرءٔ رفتارهاى خودمراقبتى در آن N/199

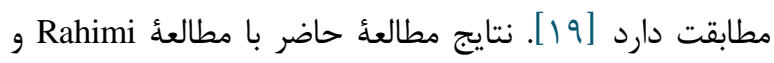

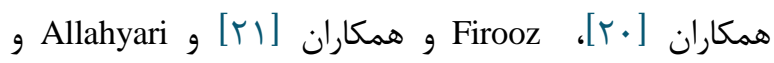

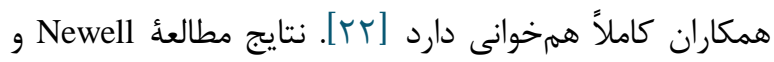
همكاران نيز رفتارهاى خودمراقبتى در بيماران مبتلان بهان يرفشارى خون را در سطح نامطلوبى ززارش كردند [بr] كه باريا

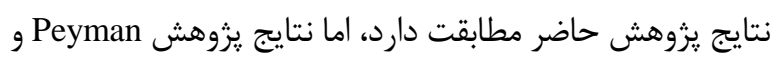

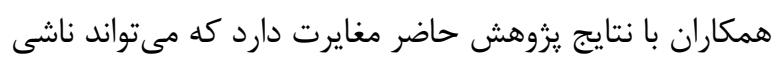

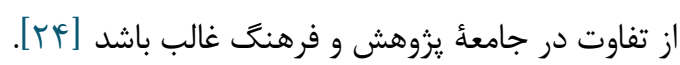
از نظر يزوهشگً وجود مسائل فرهنگى و اقتصادى در جامعه و فشارهاى روانى ناشى از آن و عدم آخاهى هاى موجود درباره عوارض سوء عدم رعايت اصول درمانى و مراقبتى سبب بروز درصد پايين رفتارهاى خودمراقبتى در جامعه شده است. در رد

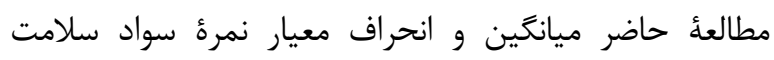

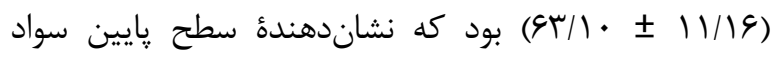
سلامت در جامعه است. نتايج مطالعة Rahmati و همكاران در 
نتايج حاصل از يزوهش حاضر نشان مىدهد بين رفتار

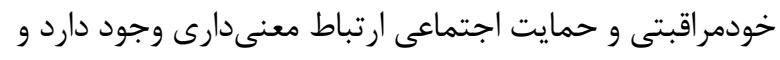

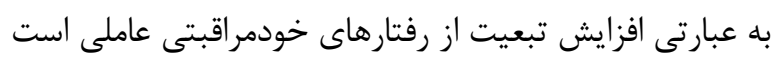

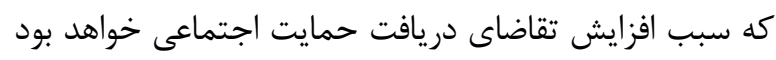

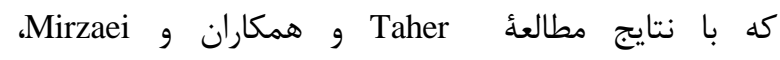
Arabi Moghimbeigi

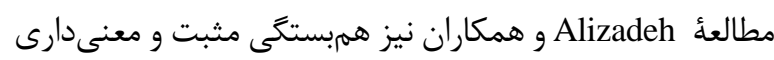

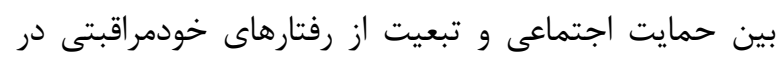

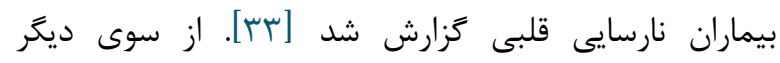
Alizadeh به نقل از راك ول مىنويسد كه حمايت اجتماعى در

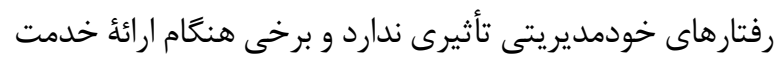

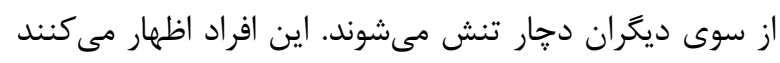

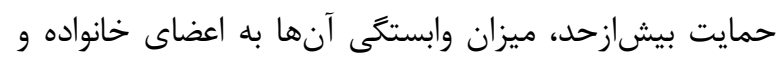

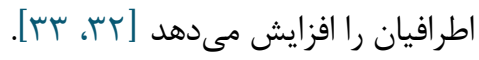

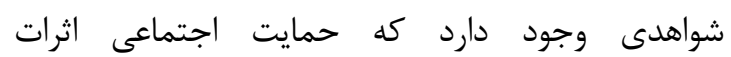
محافظت كنندهاى بر بيماران دارد. نبود حمايت اجتماعى دارد عامل

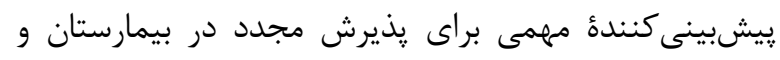

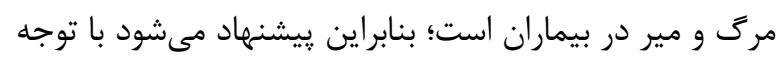

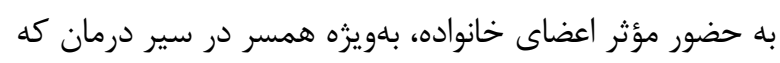

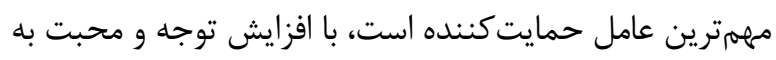

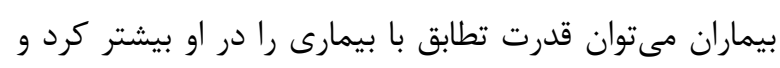

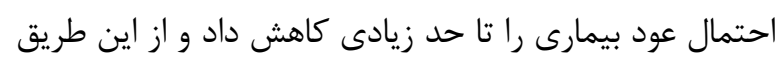

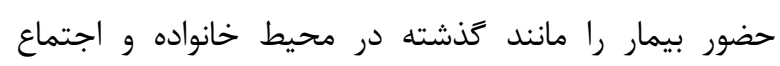

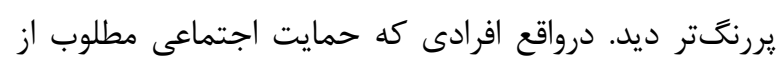

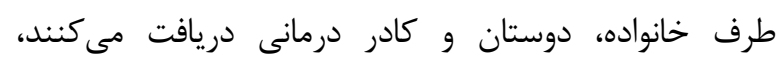

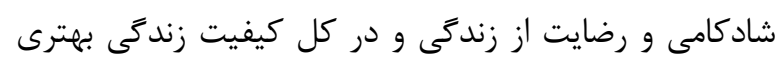

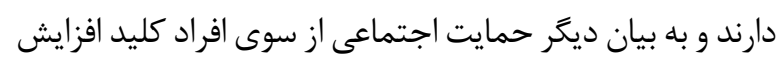

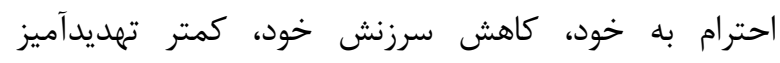
تلقى كردن بيمارى و مشكلات و سازگًارى بهتر را به دنبه دنبال دارد.

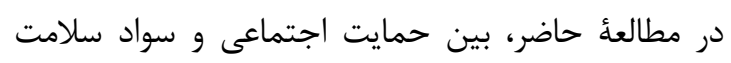

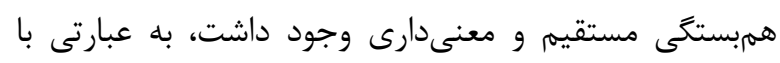
بالاتر رفتن سواد سلامت، ميزان حمايت اجتماعى بيشترى ديد ديده

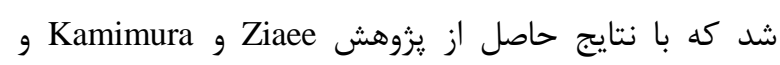

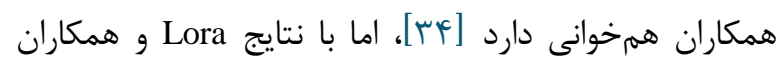

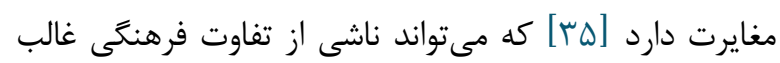
باشد. به عبارت ديكر، ارتقاى سلامت، فرايند قادرسازى افراد براى كنترل سلامتى خود و عوامل مؤثر بر آن است. افراد با سواد فاد إداد
سلامت و توليدكنندكان اطلاعات سلامت نيز بايد با شناخت

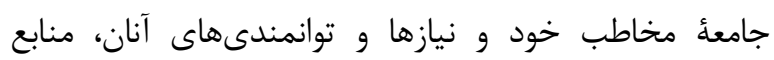

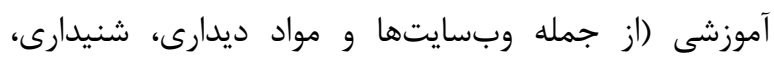

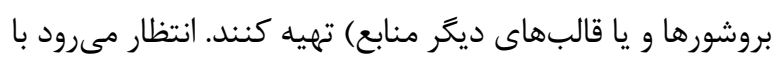

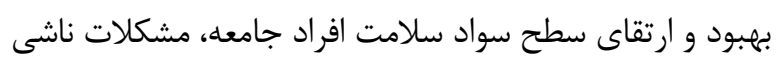
از سطح سواد سلامت ناكافى كاهش يابد.

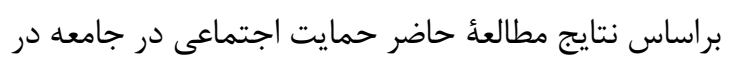

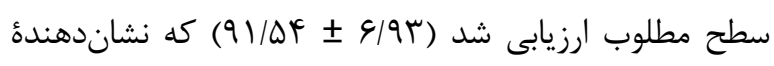

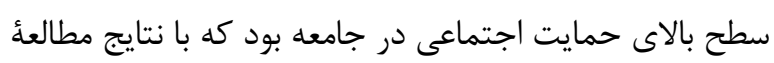

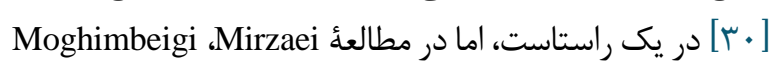

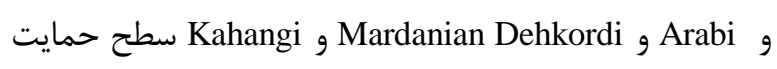
اجتماعى در سطح متوسط و وايين بود كه مىتواند ناشى از

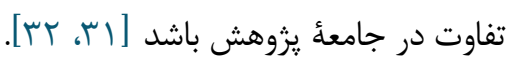

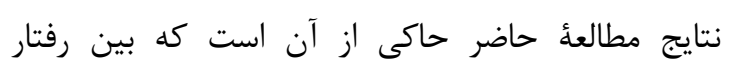

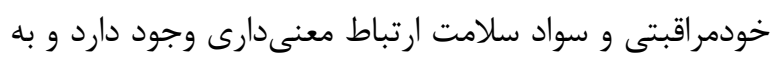

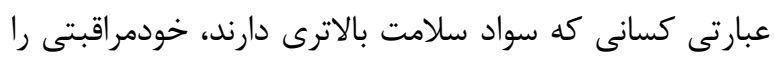

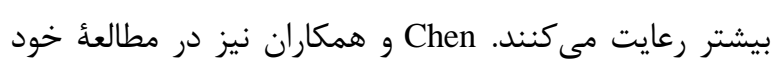

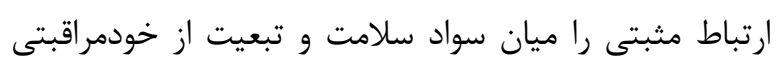

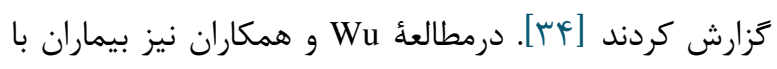

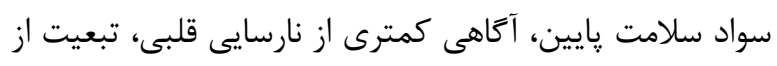

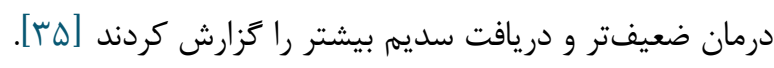

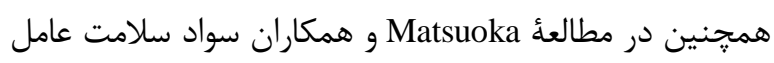
تعيين كنندة رفتار خودمر اقبتى در بيماران نارسايى قلبى و وديابت

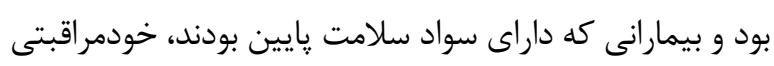

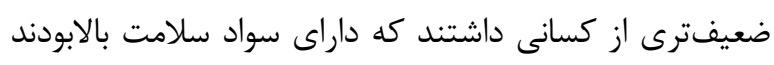

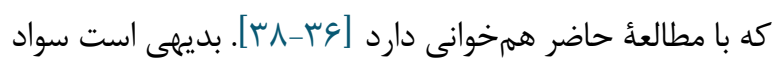

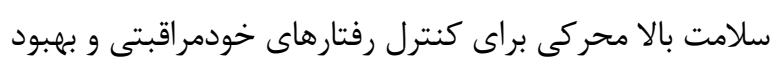

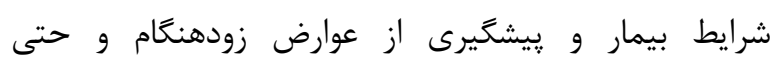
طولانىمدت بيمارى خواهد بود. اين موضوع نشان مى دهد تورجية

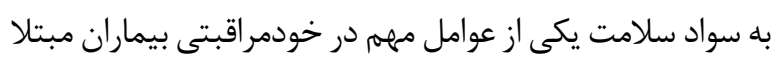

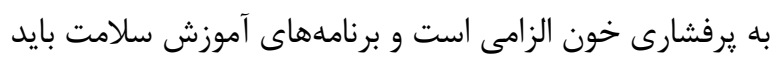

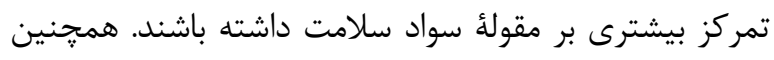

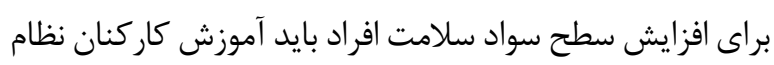

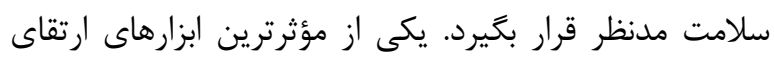

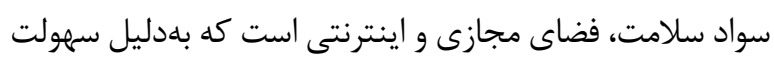

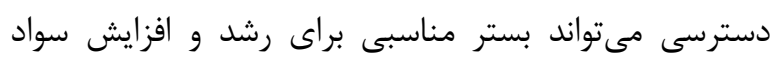
سلامت بيماران باشد.

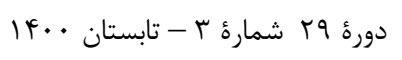


سلامت و خودمراقبتى و حمايت اجتماعى و حمايت اجتماعى

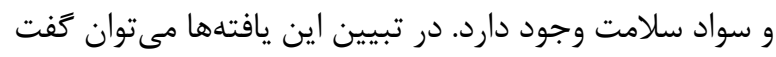

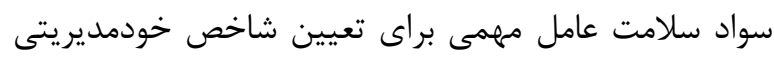

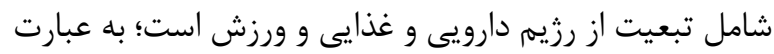
ديگر هرجه سواد سلامت فرد بالاتر باشد، درك بالاترى از بيمارى و نحؤ مراقبت خود دارد كه مى توانند علائم بيمارى

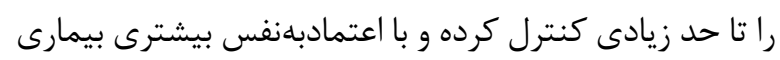

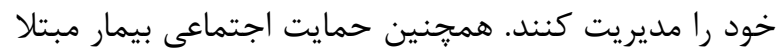

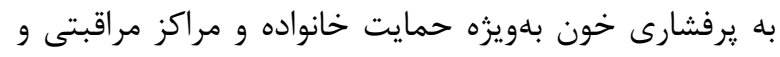

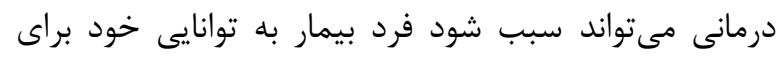

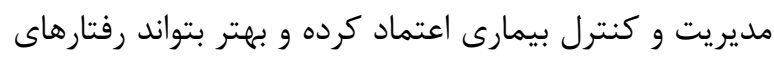

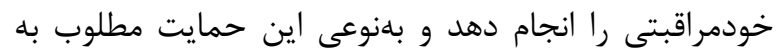
بهبود باور به اثربخشى درمان و مديريت بهتر يرفشارى خون مى انجامد.

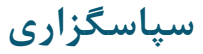

اين مقاله حاصل طرح تحقيقاتى مصوب دانشكاه علوم

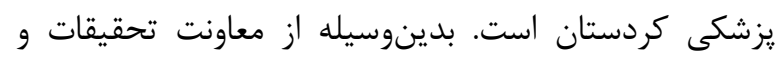

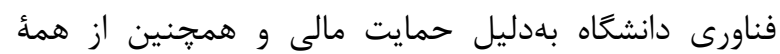

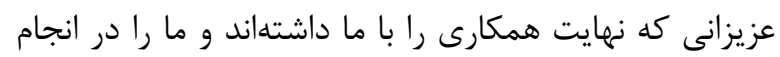

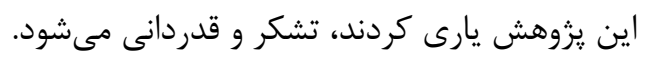

$$
\text { تعارض در منافع }
$$

بين نويسندكان مقاله، تعارض در منافعى وجود ندارد.

$$
\text { منابع مالى ندارد. }
$$

\section{References}

1. SheikhSharafi H, Seyedamini B. Assessment of health literacy and self-care in heart failure patients. J. Health Lit. 2017;1(4):203-19.

2. Avaznejad N, Ravanipour M, Bahreyni M, Motamed N. Comparison of spiritual health in mothers with healthy children and mothers of children with chronic disease in Kerman 20152016. nvj. 2016;3(8):13-25.
سلامت ناكافى توانايى كمترى در ارزيابى اطلاعات، درك كيفيت

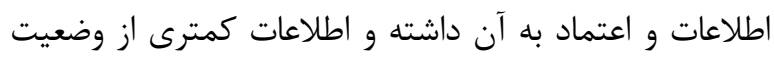

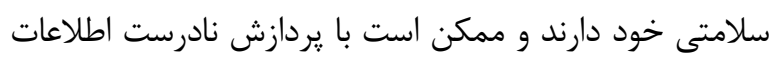

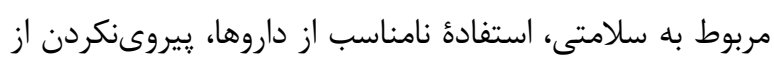

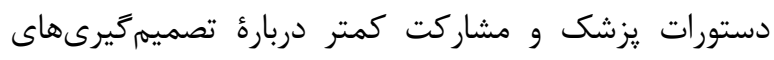

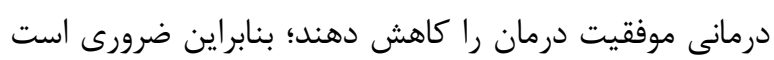

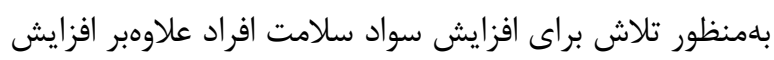

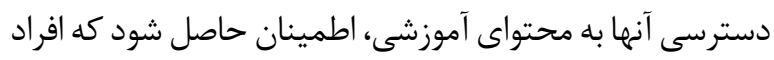

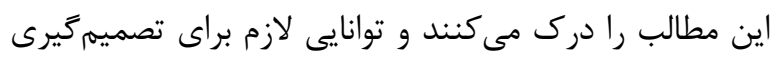

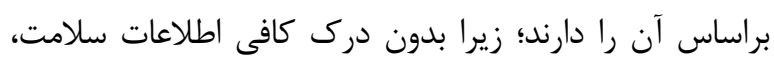

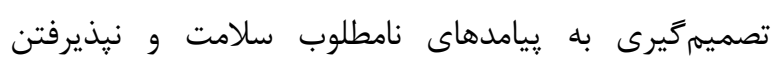

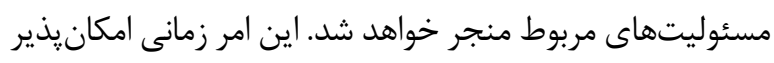

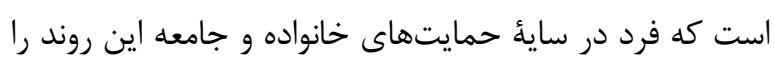

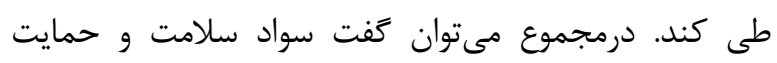

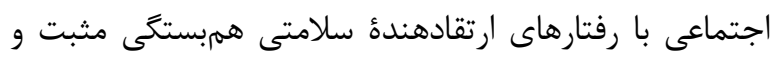

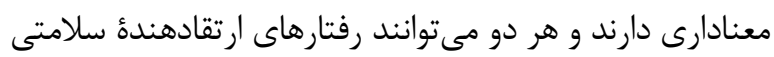

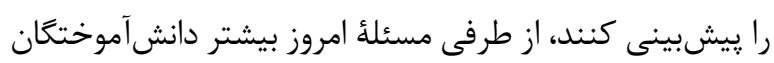

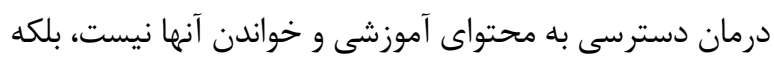

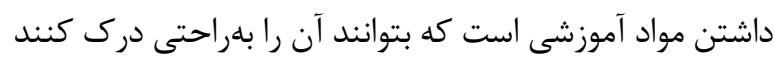

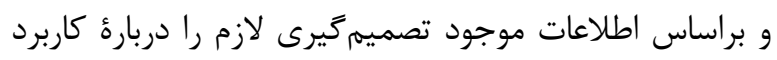

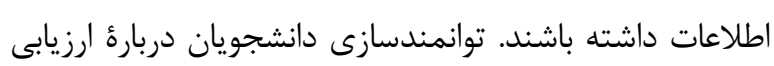

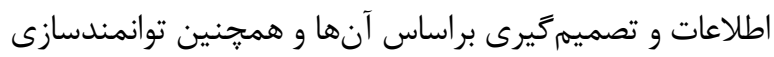

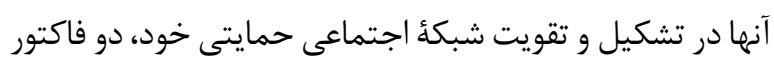

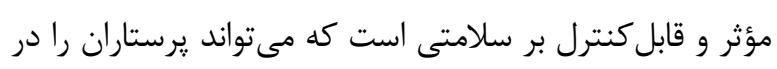
اجراكردن رفتارهاى ارتقادهنده سلامتى بيشتر يارى كنى كند.

$$
\text { نتيجه تيرى }
$$

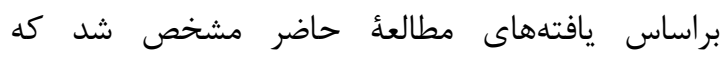

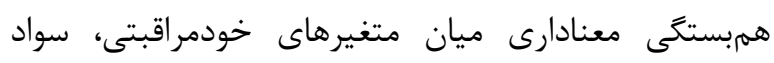

3. Hinkle JL, Cheever KH. Brunner and Suddarth's textbook of medical-surgical nursing. Wolters kluwer india Pvt Ltd; 2018;14 th ed: 884.

4. Farzad F. National Non Communicable Diseases Surveillance Survey. Endocrine \& Metabolism Research Institute Tehran University of Medical Sciences. 2016.

5. Lacruz ME, Kluttig A, Hartwig S, Löer M, Tiller $\mathrm{D}$, Greiser KH. Prevalence and Incidence of Hypertension in the General Adult Population: 
روزين بهمنى و همكاران 199

Results of the CARLA-Cohort Study. Medicine. 2015;94(22):e952.

\section{[DOI:10.1097/MD.0000000000000952]}

6. Park JB, Kario K, Wang JG. Systolic hypertension: an increasing clinical challenge in Asia. Hypertension. 2015;38(4):227-36 [DOI:10.1038/hr.2014.169]

7. Haghranjbar F, Shirzad M, Taghdisi MH, Sarami GR, Ahadi $\mathrm{H}$. The mediating role of subjectivewellbeing in terms of perceived stress and hypertension. Iran J Health Educ Health Promot. 2016;4(1):50-7.

[DOI:10.18869/acadpub.ihepsaj.4.1.50]

8. Gheshlagh RG, Parizad N, Ghalenoee M, Dalvand S, Baghi V, Najafi F, Ebadi A. Psychometric features of the persian version of self-efficacy tool for patients with hypertension. Int. Cardiovasc. Res. J. 2018;12(2):50-6.

9. Patel KV, Li X, Kondamudi N, Vaduganathan M, Adams-Huet B, GC F. Prevalence of apparent treatment-resistant hypertension in the United States according to the 2017 high blood pressure guideline. Mayo Clin. Proc. 2019;94(5):776-82. [DOI:10.1016/i.mayocp.2018.12.033]

10. Matura LA, McDonough A, Carroll DL. Symptom prevalence, symptom severity, and health-related quality of life among young, middle, and older adults with pulmonary arterial hypertension. Am. J. Hosp. Palliat. Med. 2016;33(3):214-21. [DOI:10.1177/1049909114554079]

11. Brown C, Lynch Y, Modes M, Steiner J, Leary P, RA E. Palliative Care Needs and Attitudes of Patients with Pulmonary Arterial Hypertension. Am J Respir. 2019;199(1):A1075. [DOI:10.1164/ajrccmconference.2019.199.1_MeetingAbstracts.A1075]

12. Banerjee T, Crews DC, Tuot DS, Pavkov ME, Burrows NR, Stack AG, Saran R, Bragg-Gresham J, Powe NR, Powe N, Tuot D. Poor accordance to a DASH dietary pattern is associated with higher risk of ESRD among adults with moderate chronic kidney disease and hypertension. Kidney Int. 2019;95(6):1433-42.

\section{[DOI:10.1016/j.kint.2018.12.027]}

13. Ovayolu OU, Ovayolu N, Karadag G. The relationship between self-care agency, disability levels and factors regarding these situations among patients with rheumatoid arthritis. JCN. 2012. 21(1): 10-101. [DOI:10.1111/j.13652702.2011.03710.x]

14. Tanimura $\mathrm{C}$, Matsumoto $\mathrm{H}$, Tokushima $\mathrm{Y}$, Yoshimura J, Tanishima S, Hagino H. Self-care agency, lifestyle, and physical condition predict future frailty in community-dwelling older people. Nurs Health Sci. 2018;20(1):31-8 [DOI:10.1111/nhs.12376]

15. Rezaei H, Jamil DI, Ebadi A, Gheshlagh RG. Psychometric Properties of the Persian Version of the Instrument for Assessing Cardiac Patients'
Knowledge, Attitude, and Beliefs regarding Heart Attack. Int. Cardiovasc. Res. J. 2019;13(2):62-8.

16. Rush KL, Hatt L, Janke R, Burton L, Ferrier M, Tetrault M. The efficacy of telehealth delivered educational approaches for patients with chronic diseases: A systematic review. Patient Educ Couns. 2018;101(8):1310-21. [DOI:10.1016/j.pec.2018.02.006]

17. Nam S, Chesla C, Stotts NA, Kroon L, Janson SL. Barriers to diabetes management: patient and provider factors. Diabetes Res Clin Pract J. 2011; 96(1): 1-9. [DOI:10.1016/j.diabres.2011.02.002]

18. Ingram RR, Ivanov LL. Examining the association of health literacy and health behaviors in African American older adults: does health literacy affect adherence to antihypertensive regimens?. J Gerontol Nurs. 2013;39(3):22-32 [DOI:10.3928/00989134-20130201-01]

19. Shabibi P, Mansourian M, Abedzadehzavareh M, Sayehmiri K. The status of self-care behaviors in patients with type 2 diabetes in the city of Ilam in 2014. J Ilam Univ Med Sci. 2016; 24(2):63-71. [DOI:10.18869/acadpub.sjimu.24.2.63]

20. Rahimi MA, Izadi N, Rezvan Madani F, Eghbalian A. Knowledge and practice level of self-directed care among diabetics in Kermanshah city in 2014: a short report. J. Rafsanjan Univ. Med. Sci. Health Serv. 2015;14(2):167-72.

21. Firooz M, Hosseini SJ, Mazlom SR, Hasan Zadeh F, Kimiyaee SA. Self-care of patient with diabetes type II. J Sabzevar Univ Med Sci. 2016;22(6):1018-25.

22. Allahyari J, Shirani N, Sargolzaei MS, Jafari J, Afshari J. Self-care behavior and rrelated factors of patients with diabetes type II in Saravan in 2017. J. Diabetes Nurs. 2018 Oct 10;6(3):550-7.

23. Newell M, Modeste N, Marshak HH, Wilson C. Health beliefs and the prevention of hypertension in a black population living in London. Ethn. Dis. 2009 1;19(1):35-41.

24. Peyman T, Pirzadeh A, Hasnzadeh A, Mostafavi F. The Relationship of Self-Care Behaviors and Health Literacy in Patients with Hypertension in Isfahan City, Iran, in 2015-2016. J Health Syst Res. 2017;13(3):381-7.

25. Rahmati M, Rejeh N, Heravi-Karimooi M, Tadrisi D. Investigating the Relationship between Health Literacy and Adherence with Treatment Regimen in the Elderly with Hypertension. IJNR. 2018;13(5):15-21.

26. Marzangi A, Ahangarzadeh Rezaei S, Ghareagaji Asl R. Health Literacy In Heart Disease Community Coverd By Health Services Centers In South Of West Aarbaijan Province. J Clin Nurs Midwifery. 2018;16(1):45-54.

27. Warren-Findlow J, Hutchison J, Patel P, Dulin M, Tapp H, Kuhn L. Assessing health literacy of hypertensive patients in a primary care setting

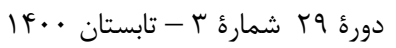


using a self-administered questionnaire. J Health Care Poor Underserved.2014; 25(4): 1833-43. [DOI:10.1353/hpu.2014.0187]

28. Seyedoshohadaee M, Barasteh S, Jalalinia F, Eghbali M, Nezami M. The relationship between health literacy and self-care behaviors in patients with type 2 diabetes. Iran $\mathbf{J}$ Nurs Res. 2016;4(10):43-51.

29. Rafiezadeh GS, Tabarsy B, Hassanjani S, Razavi M, Amjady M, Hojjati H. Relationship between the health literacy with selfefficacy of the diabetic patient's type 2 referred to Gorgan city clinic in. J Diabetes Nurs. 2014;2(2):30-42.

30. Saadati M, Guidance M. Relation between family social support \& coping strategies in recovery breast cancer. Iran J Breast Dis. 2014; 6(4):35-40.

31. Mirzaei Z, Moghimbeigi A, Arabi A. The correlation between social support and management of hypertension in menopausal females at the Farshchian hospital, Hamadan. Avicenna J Nurs Midwifery Care. 2017 Jul 10;25(2):75-83. [DOI:10.21859/nmj-250210]

32. Mardanian Dehkordi L, Kahangi LS. Relationship between structural and contextual dimensions in organizational structure of ZahedanKhatamolanbia hospital. J Health Syst Res. 2015; 11(2):229-38.

33. Chen AM, Yehle KS, Albert NM, Ferraro KF, Mason HL, Murawski MM, Plake KS. Relationships between health literacy and heart failure knowledge, self-efficacy, and self-care adherence. Res Social Adm Pharm. 2014;10(2):378-86.

[DOI:10.1016/j.sapharm.2013.07.001]

34. Lora CM, Gordon EJ, Sharp LK, Fischer MJ, Gerber BS, Lash JP. Progression of CKD in Hispanics: Potential roles of health literacy, acculturation, and social support. Am J Kidney Dis. 2011;58(2):282-90. [DOI:10.1053/j.ajkd.2011.05.004] 